\title{
Impact of Dams on Groundwater Static Water Level Changes: a Case Study Kralkızı and Dicle Dam Watershed
}

\begin{tabular}{|ccc|}
\hline \multicolumn{3}{|c|}{ Recep ÇELIK $^{* 1}$} \\
\hline \\
\hline Department of Civil Engineering, Dicle University, 21280, Diyarbakir, Turkey. \\
\hline & & \\
\hline Bassvuru/Received: $05 / 10 / 2017$ & Kabul/Accepted: $27 / 05 / 2018$ & Son Versiyon/Final Version: $29 / 06 / 2018$ \\
\hline
\end{tabular}

\begin{abstract}
Dams are expected to raise the groundwater, especially the ones surrounding of lake. However, it should be investigated the influences of dams on the groundwater through lower basin. In this study, the effects of Kralkizi and Dicle dams on groundwater were investigated in the sub of the Dam's basin. The reason behind the selection of Dicle and Kralkizi dams is that, apart from hydroelectric production, they provide agricultural irrigation and potable water in catchment basins. Agricultural irrigation is provided by water wells and groundwater springs in upper Diyarbakir plain where these dams are built in. The wells logs opened the years between 1996 and 2011 have been examined inside the dam's basin. The drilling data were ranked with the aid of Microsoft Excel software, and the coordinates have been arranged accordingly. These data were run on the ARC Info 10.2.1 GIS software and the data have been modeled using Arc Info Spatial Analyze extension. Static water level maps relevant to the years 1996-2011 have been obtained through all these processes. Therefore, changes in the groundwater levels with respect to the years have been detected with these maps.
\end{abstract}

\section{Key Words}

Groundwater, GIS, Dicle and Kralkizi Dams 


\section{INTRODUCTION}

Most dams are built to produce electricity, store water for irrigation, control flood hazards, or other uses. Farther-reaching consequences of dams include provide water for domestic municipal purposes and recharge groundwater flow (Ashraf et al.2000). Dams keep the water in the lowest point, in order to provide water that irrigates cultivated areas in the dry seasons. In this situation, dams decrease the using of groundwater; hence, the groundwater increases in the underside. Operating of reservoir generally affect surface flow characteristics and its relation between surface water. Furthermore; groundwater are also affected by it like changing in feeding-discharge relations. These effects cause to the changes in the level of water panel, particularly they changes quantity of water that is used for the humanity. The direct effect of dams to the groundwater is expected to be between upstream and downstream. Moreover, it is an ordinary situation that it raises the groundwater in reservoir surfaces (Winter, 1999). However, there a few study that has been done in Dicle basin about the effects of it when it gets further away from the reservoir areas. The studies that have been done by Çelik are respectively about the change of groundwater in Dicle basin and the potential of groundwater in Diyarbakır city center (Çelik 2014, Çelik 2015).

Within dams, trends were strongly linked with the differing water sources, evidenced by chemical patterns that matched those expected from the different dominant ion transfer pathways associated with surface water and groundwater flow processes. There are many researches about environmental impact of dam, exclusively the quality of groundwater, salinity and impact of $\mathrm{Ph}$ in the literature [Baxter, 1977, Sinorot et al.,1995, Martinez et al.,2013), Brainwood et al., 2004, Elango, 2014). These studies claim that dams cause salinizing in groundwater and affects quality of water affirmatively.

On the other hand, some studies analyze seepage losses in reservoirs and its impact on groundwater and surface waters. They show that decreasing the volume of dam's reservoir caused to increase the groundwater level in the coast of dams (Westbrook et al., 2006, Malkawi et al., 2000, Turkmen, 2003, Keller et al., 2000,).

\section{MATERIAL AND METHODS}

\subsection{Study area}

Dicle and Kralkızı dams are integrated projects. These facilities are located within the provincial territory of Diyarbakır, and are 50 kilometers away from Diyarbakır city center. The Dicle Dam and the hydroelectric power plant are built on the Maden River, and 22 kilometers downstream of the Kralkızı Dam. The dam was completed in 1997. Dicle Dam is designed to ultimately irrigate 128,080 hectares (Wikipedia). It has provided about $85 \%$ of the drinking water for the city Diyarbakir since 2001. The dam has an installed hydroelectric capacity of 110 MW. Kralkızı dam was constructed between 1985 and 1997 (Ashraf et al., 2007). Kralkızı Dam serves as a storage unit for the Dicle Dam. The hydroelectric power plant has a total installed power capacity of 94 MW.

The latitude of the site is $38,668453^{\circ} \mathrm{N}$ and the longitude is $40,201243^{\circ} \mathrm{E}$.Kralkız dam is located on the Maden Stream, one of the important tributaries of the Tigris River, at a distance of 81 kilometers to Diyarbakır and 6 kilometers to the township Dicle (Figure 1). The latitude of the site is $38,369753^{\circ} \mathrm{N}$ and the longitude is $39,979597^{\circ} \mathrm{E}$.

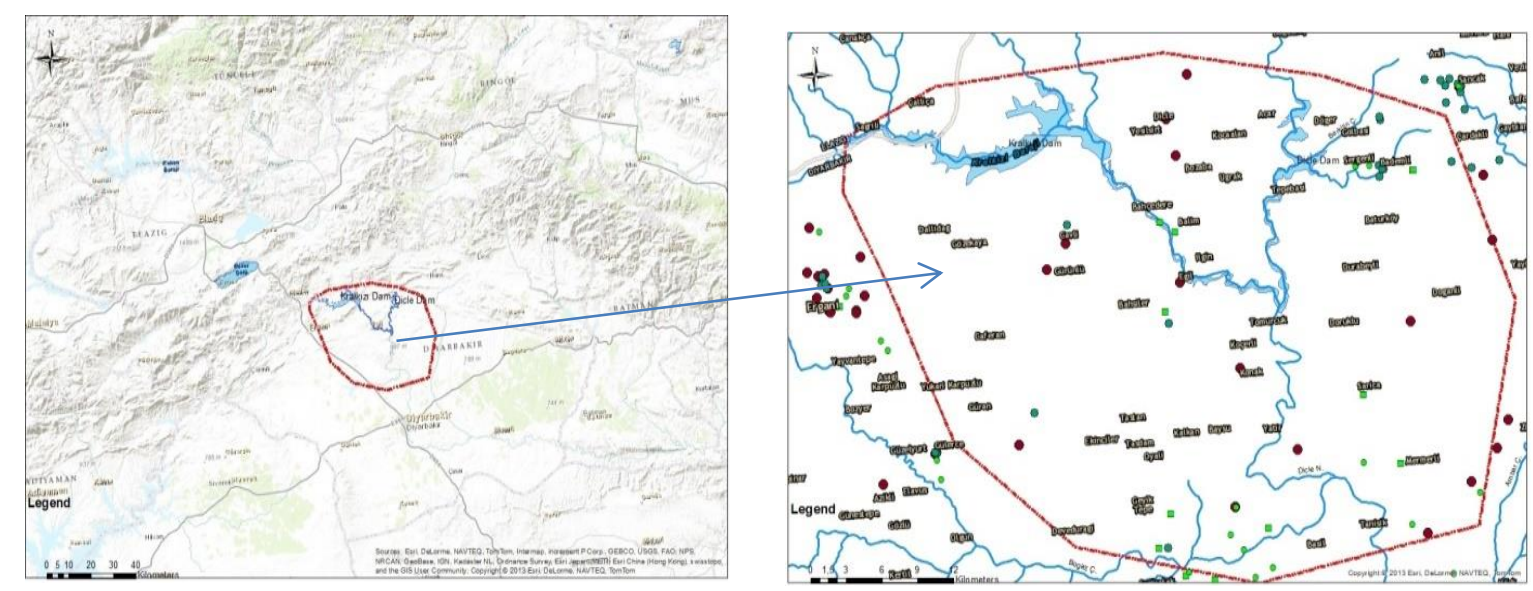

Figure 1. Dicle-Kralkıı dam location Map

\subsection{Method}

In the study, 89 wells which drilled by public institutions and private persons for watering purposes between the years 1995-2011 have been analyzed. Data of 1996 and 2008 are unavailable. So the mention years doesn't considered. Available well data are assorted by opening years with the aid of Microsoft Excel software, and the coordinates have been arranged accordingly. 11 reference points appointed that points are accepted virtual observation values. The Static Water Level (SWL) value of these points is designated ARC Map 10.2.1 software with Spatial Analyzed extension "Naturel Neighbor Interpolation" method and doing interpolation for every year. In the following maps, a basemap has been prepared through "Open Street Maps and Contributes" 
found under the Arc Info software. UTM Datum 195037 has been used as a projection. Between the Figure 2.a and 2n is created to find equal elevation SWL maps values. As Figure 2.a show the years 1995 SWL elevation map, Figure 2.b; the years 1997 SWL elavation map, Figure 2.c; the years 1998 SWL elevation map, Figure 2.d; the years 1999 SWL elevation map, Figure 2.e; the years 2000 SWL elevation map, Figure 2.f; the years 2001 SWL elevation map, Figure 2.h; the years 2002 SWL elevation map, Figure 2.i; the years 2003 SWL elevation map, Figure 2.j; the years 2004 SWL elevation map, Figure 2.k; the years 2005 SWL elevation map,Figure 2.1; the years 2006 SWL elevation map, Figure 2.m; the years 2007 SWL elevation map, Figure $2 . n$; the years 2009 SWL elevation map, Figure 2.o; the years 2010 SWL elevation map, Figure 2.o; the years 2011 SWL elevation map.

Moreover, virtual observation well referencesvalue is detected with decided year value and periodically and graphically changing in SWL at the Figure 3-8. As References 1 and 2 wells SWL (static water level) changes by the year showed in Figure 3, References 3 and 4 in Figure 4,

References 5 and 6 SWL in Figure 5, References 7 and 8 SWL in Figure 6, References 9 and 10 SWL in Figure 7, References 11 and 12 SWL showed in Figure 8

\section{RESULTS}

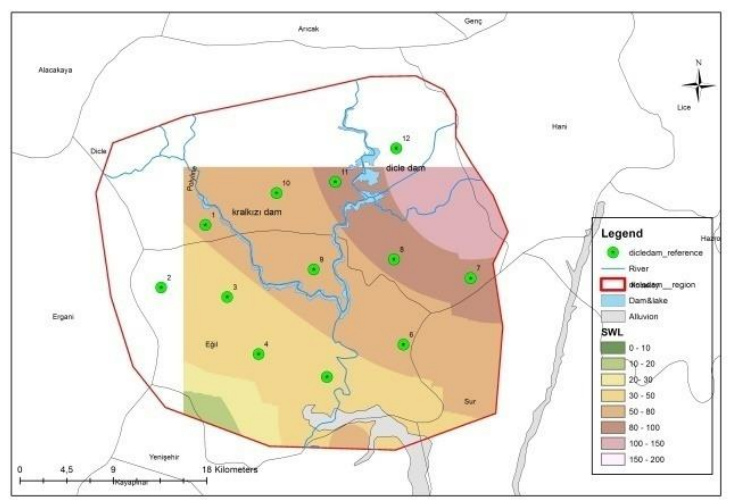

Figure 2.a1995'sSWL elevation map

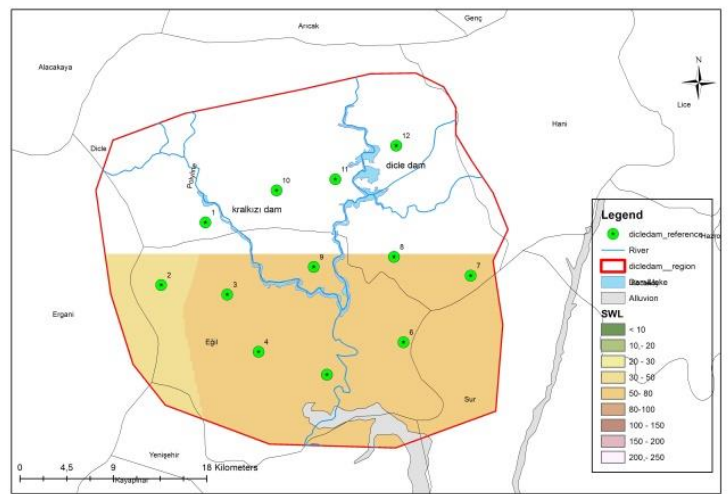

Figure2.c.1998's SWL elevation map

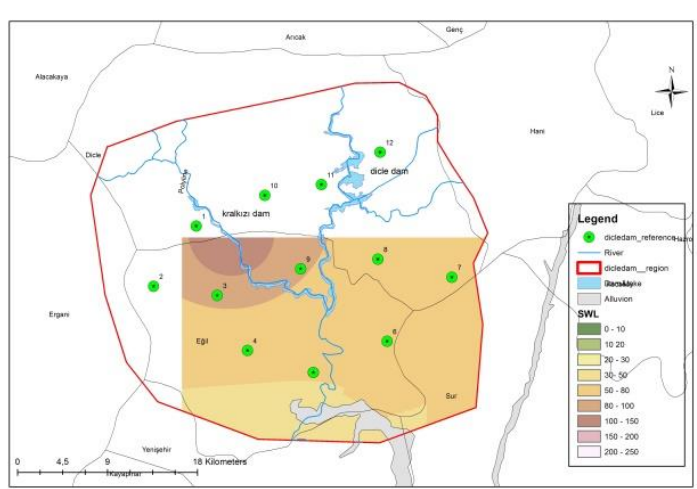

Figure 2.e.2000's SWL elevation map

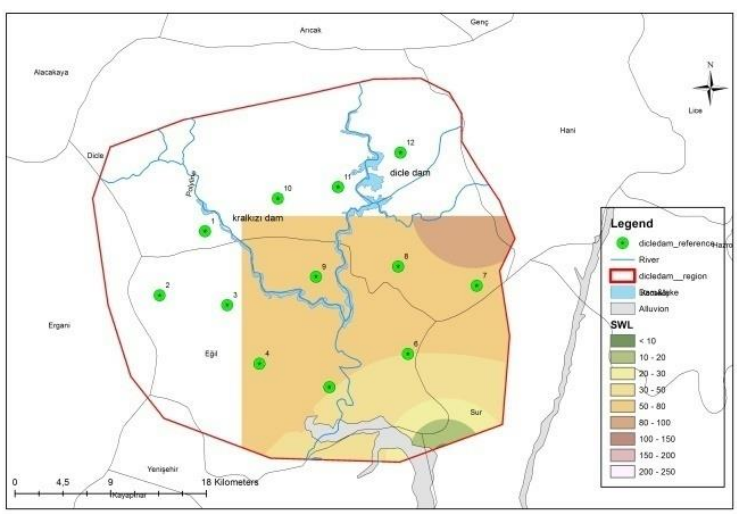

Figure2.b1997's SWL elevation map

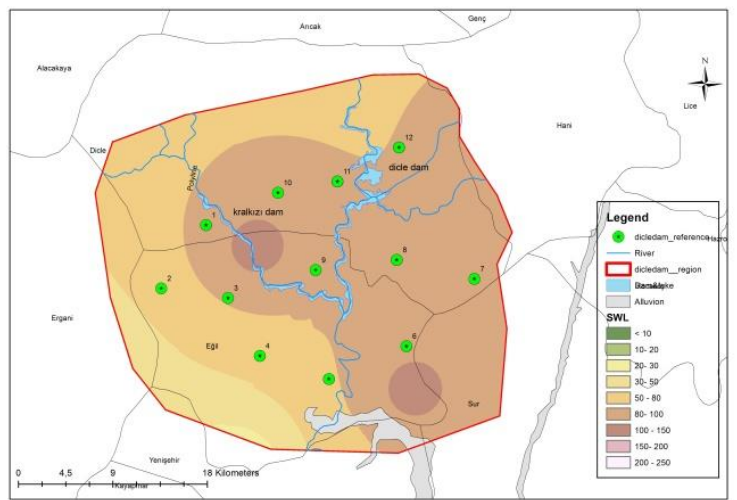

Figure2.d.1999's SWL elevation map

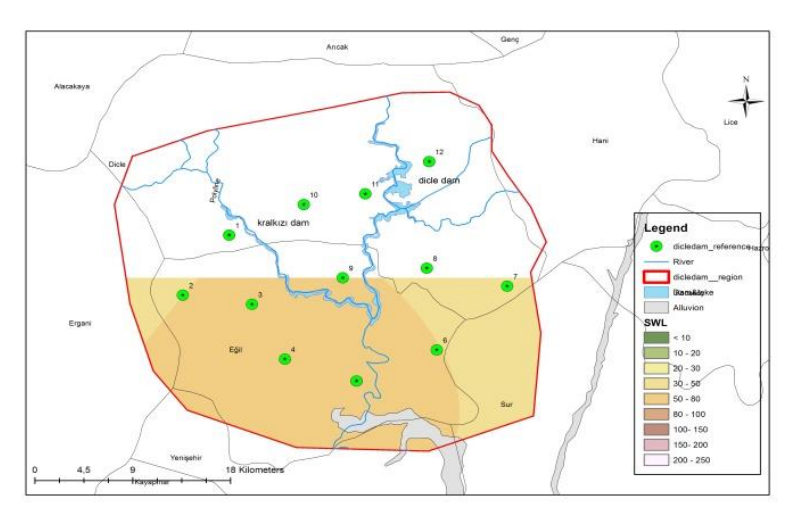

Figure 2.f.2001's SWL elevation map 


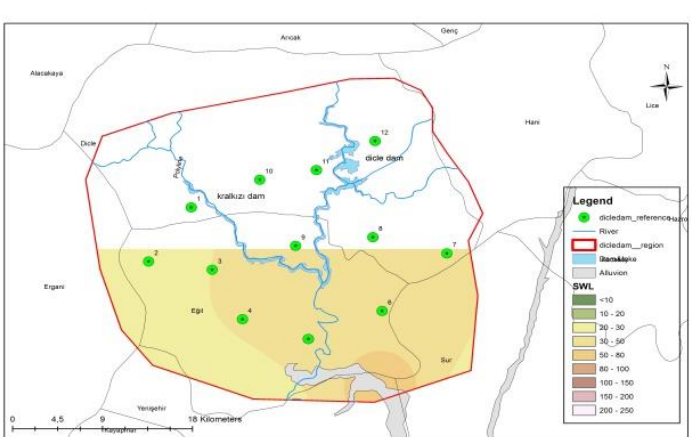

Figure2h.2002's SWL elevation map

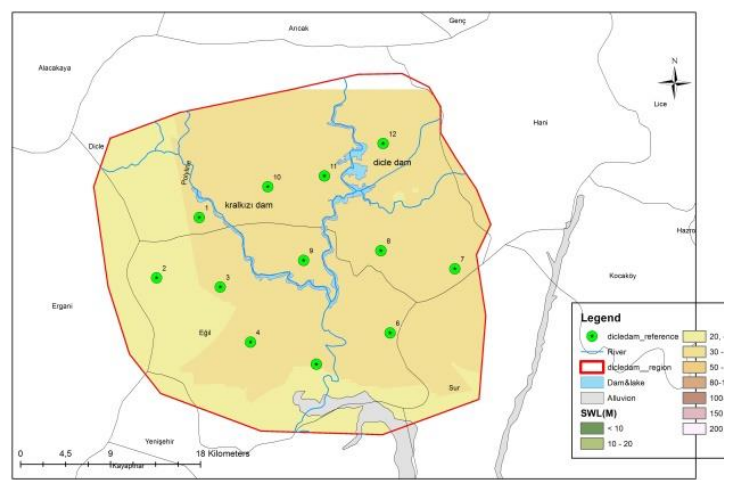

Figure 2.j. 2004's SWL elevation map

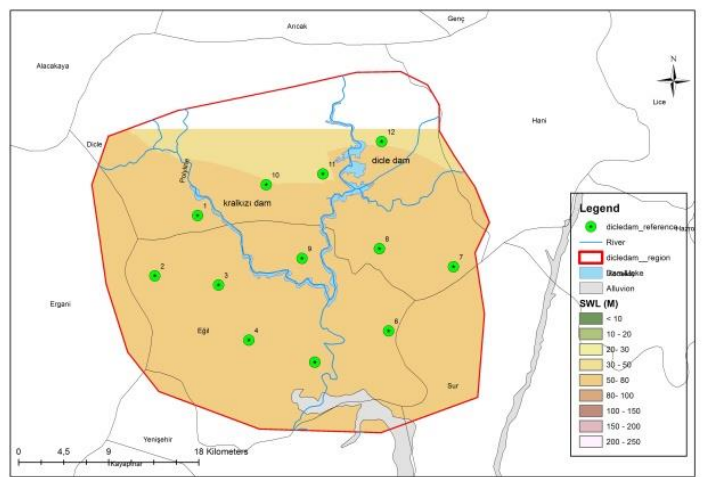

Figure 2.l. 2006's SWL elevation map

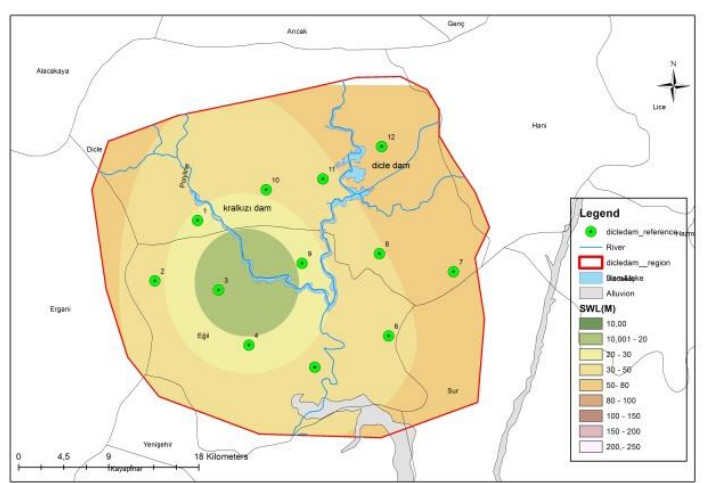

Figure 2.n. 2009's SWL elevation map

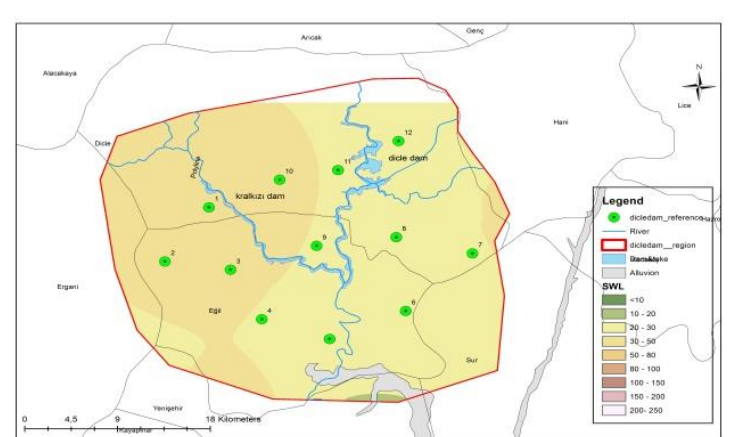

Figure 2.i .2003's SWL elevation map

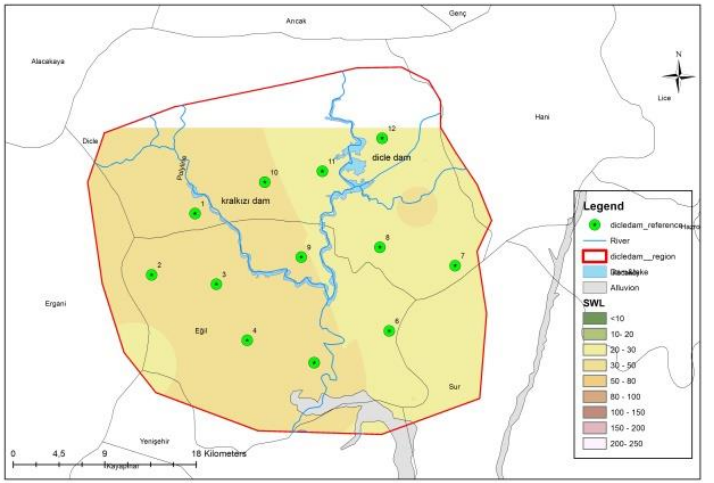

Figure 2.k. 2005's SWL elevation map

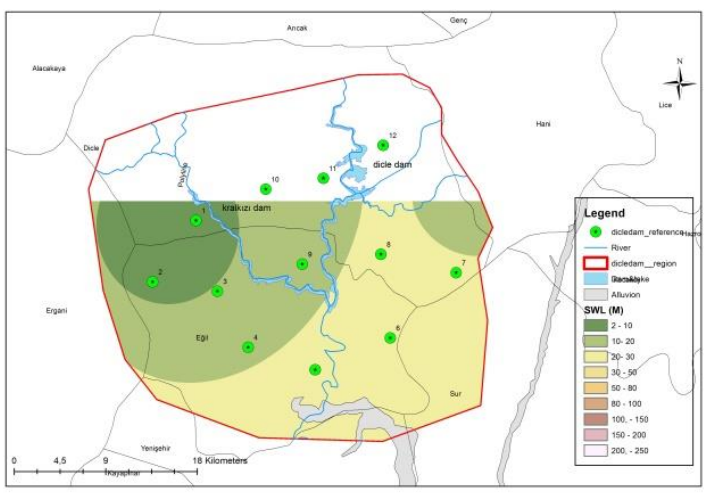

Figure 2.m.2007's SWL elevation map

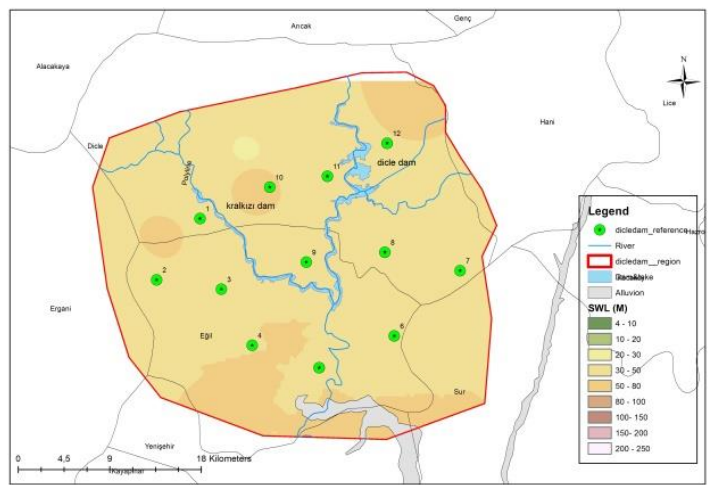

Figure 2.o. 2010's SWL elevation map 


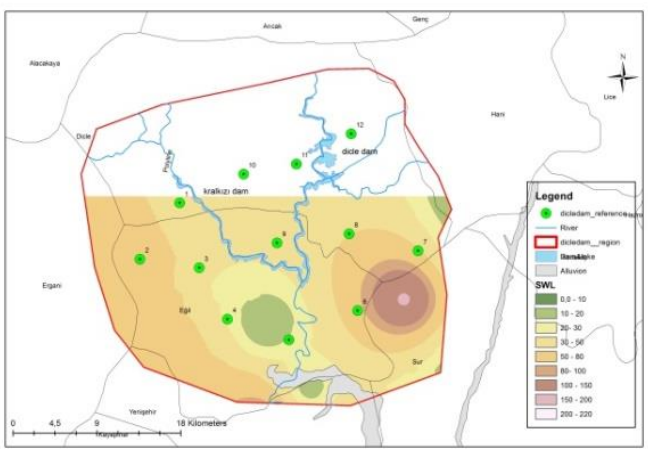

Figure 2.p 2011's SWL elevation map

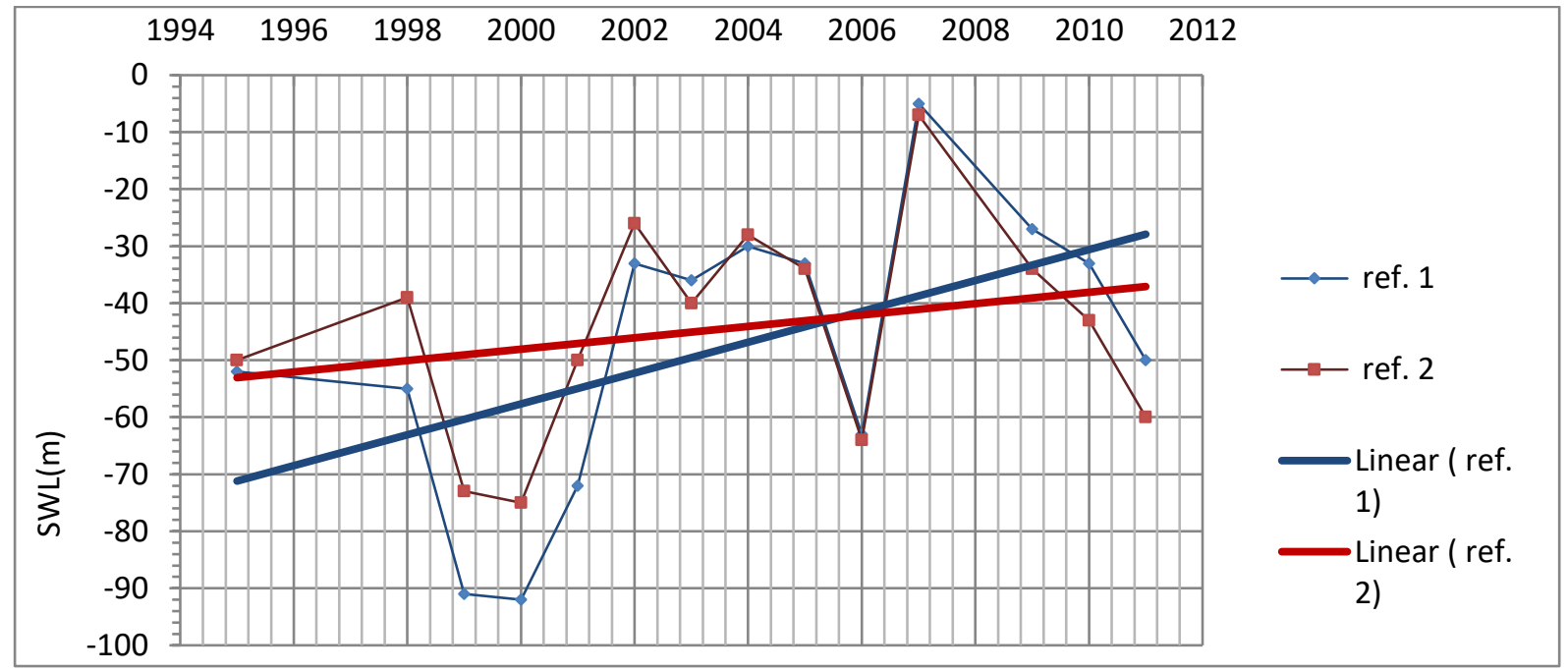

Figure 3: References 1 and 2 SWL (static water level) changes by the year

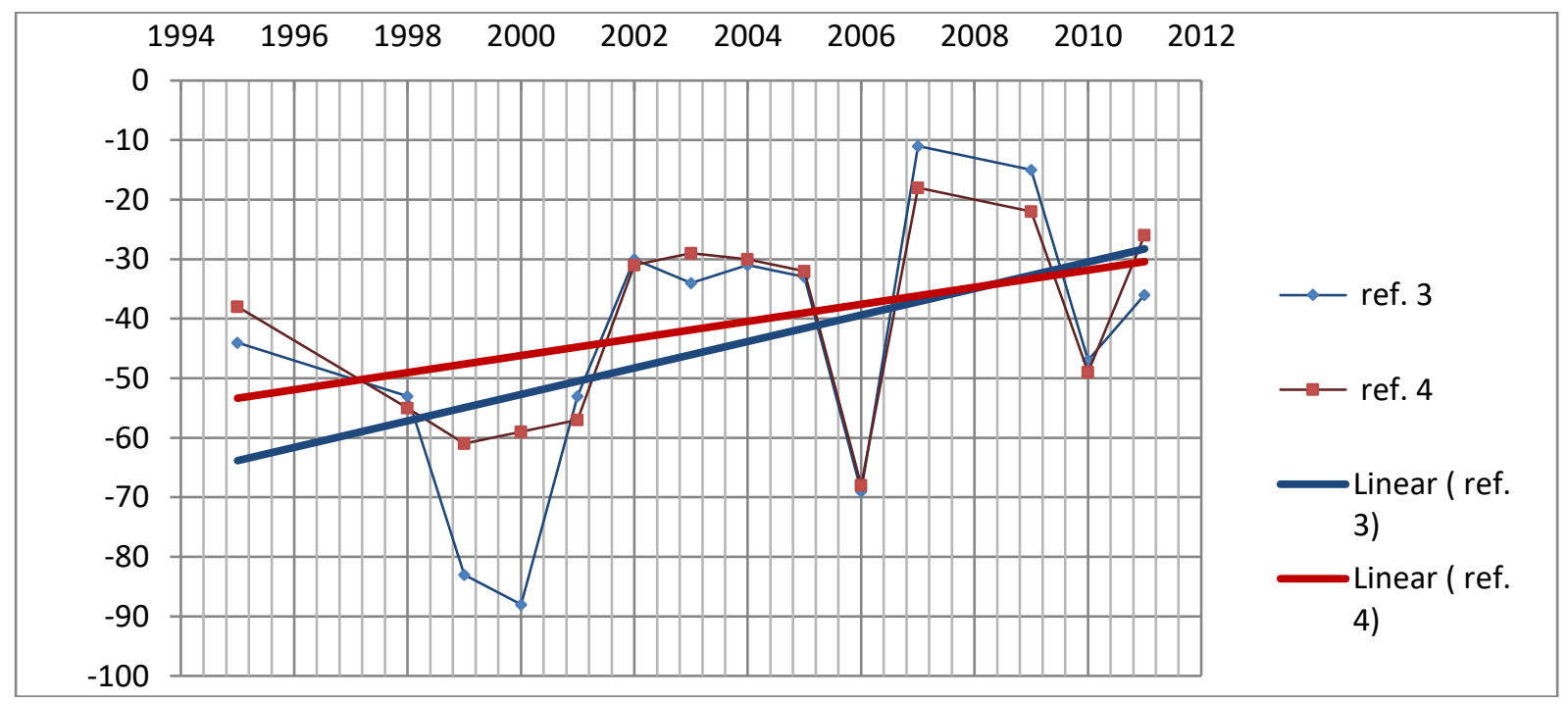

Figure 4: References 3 and 4 SWL (static water level) changes by the year 


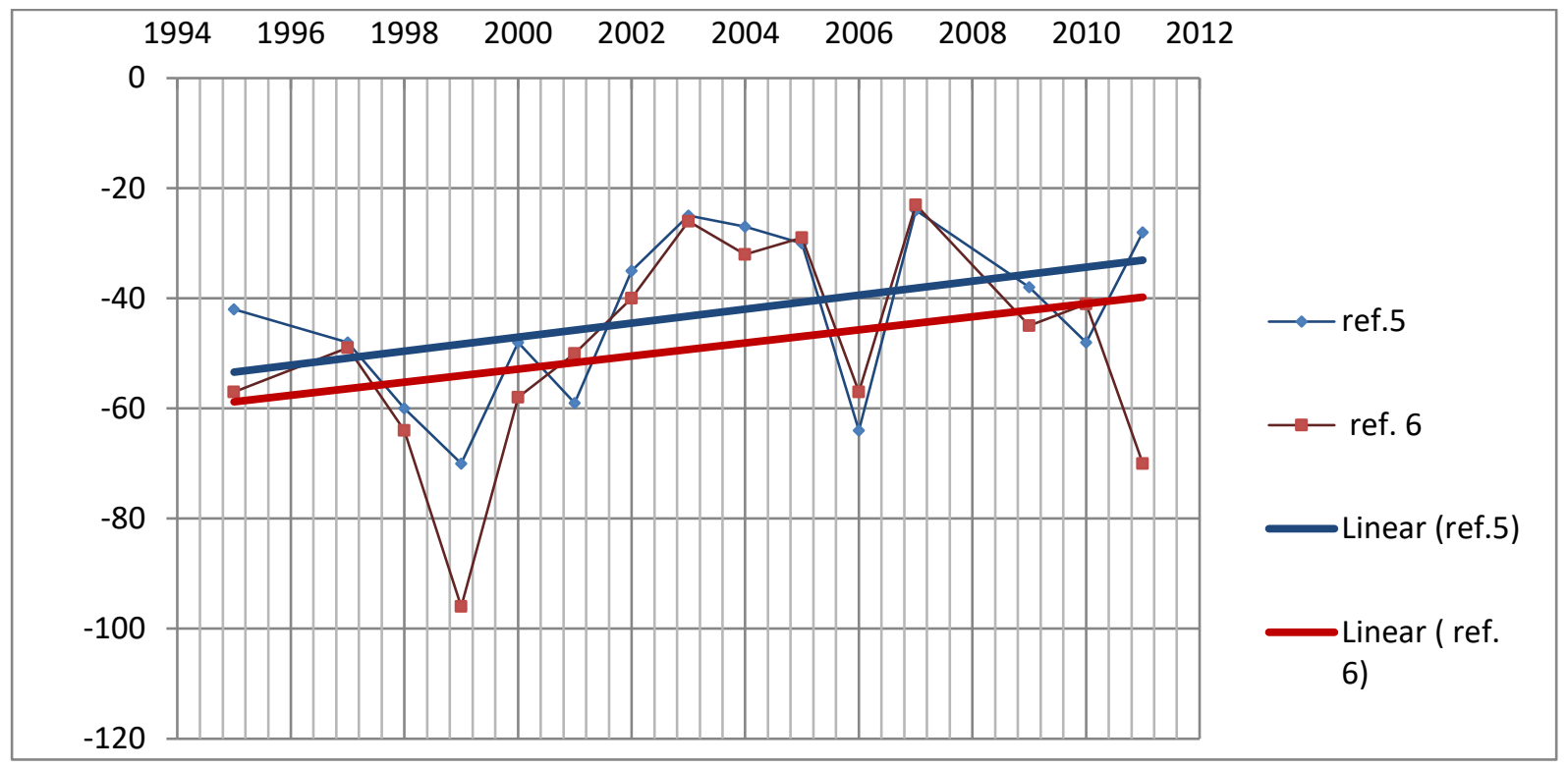

Figure 5: References 5 and 6 SWL (static water level) changes by the year

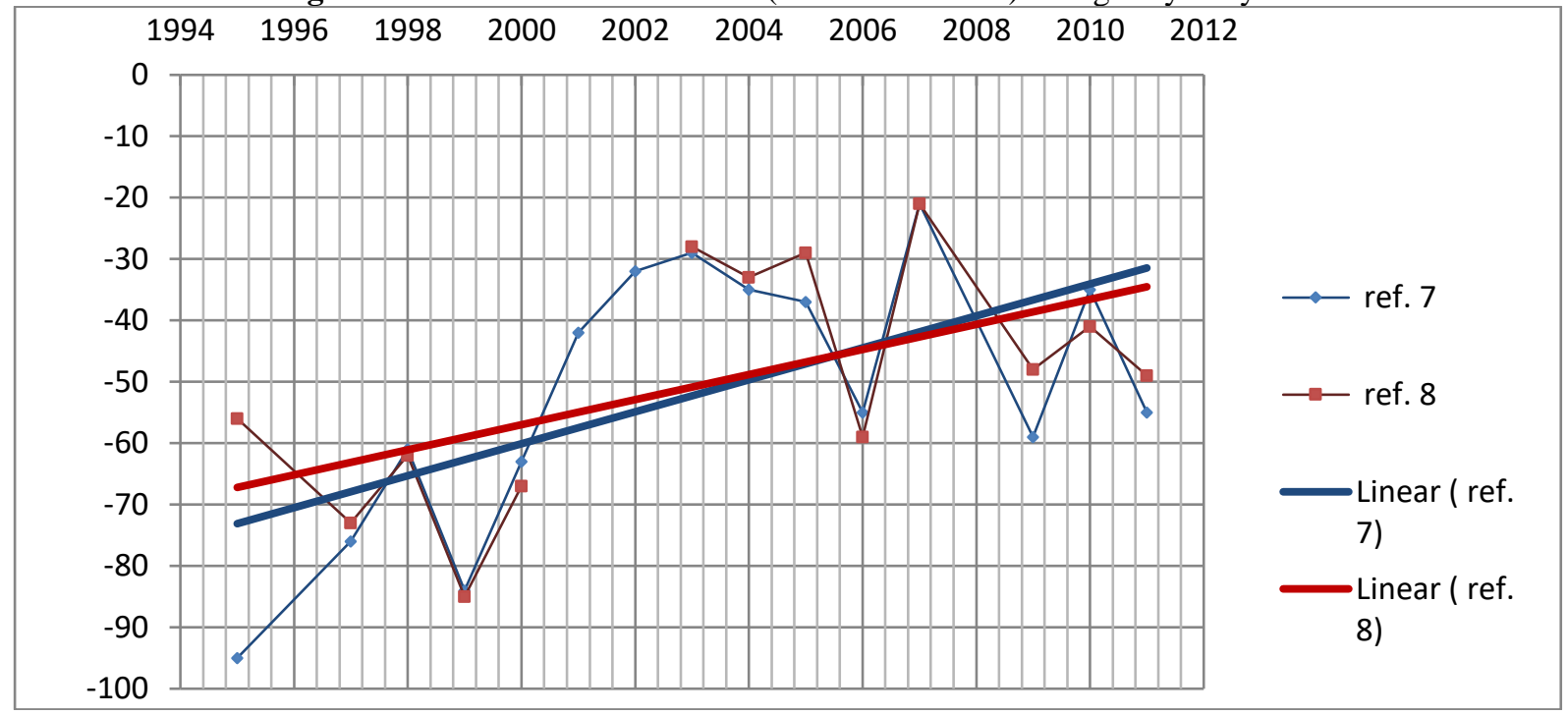

Figure 6: References 7 and 8 SWL (static water level) changes by the year

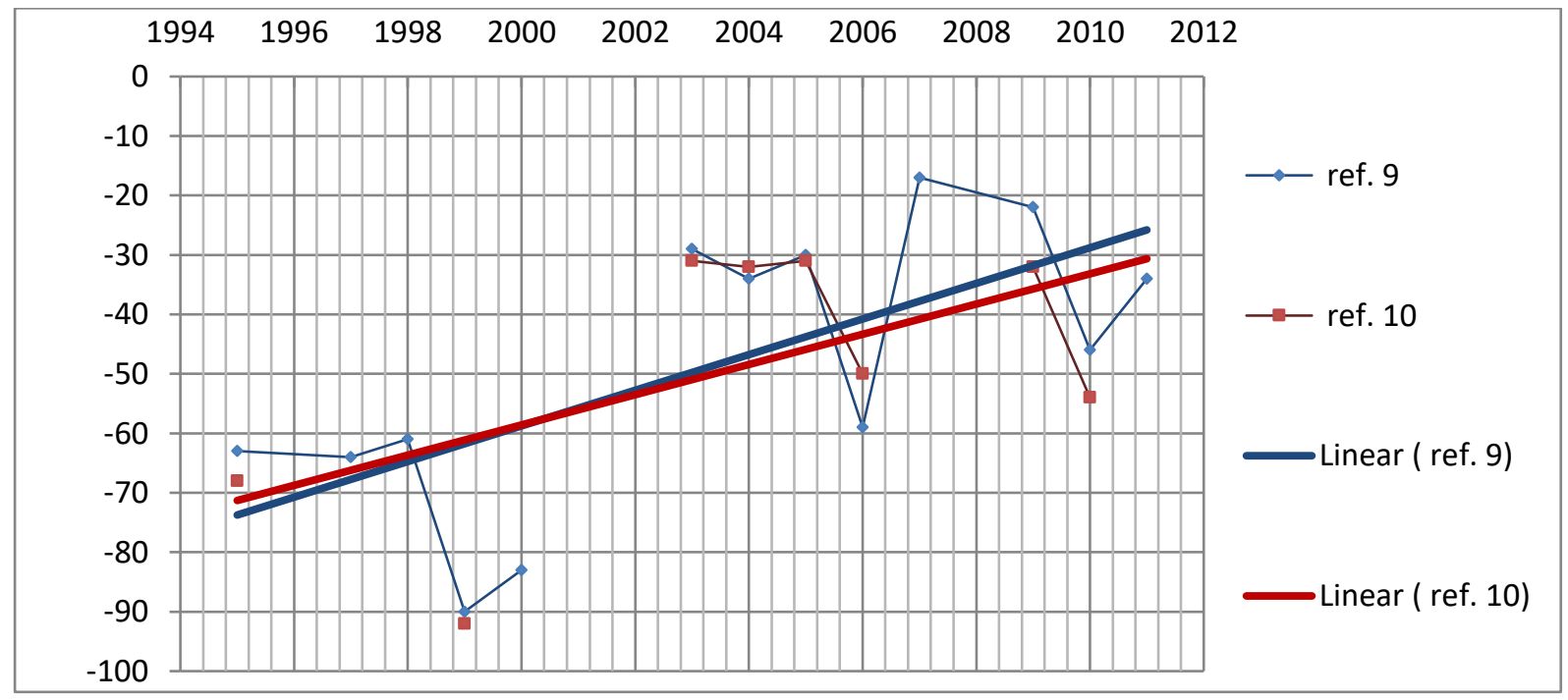

Figure 7: References 9 and 10 SWL (static water level) changes by the year 


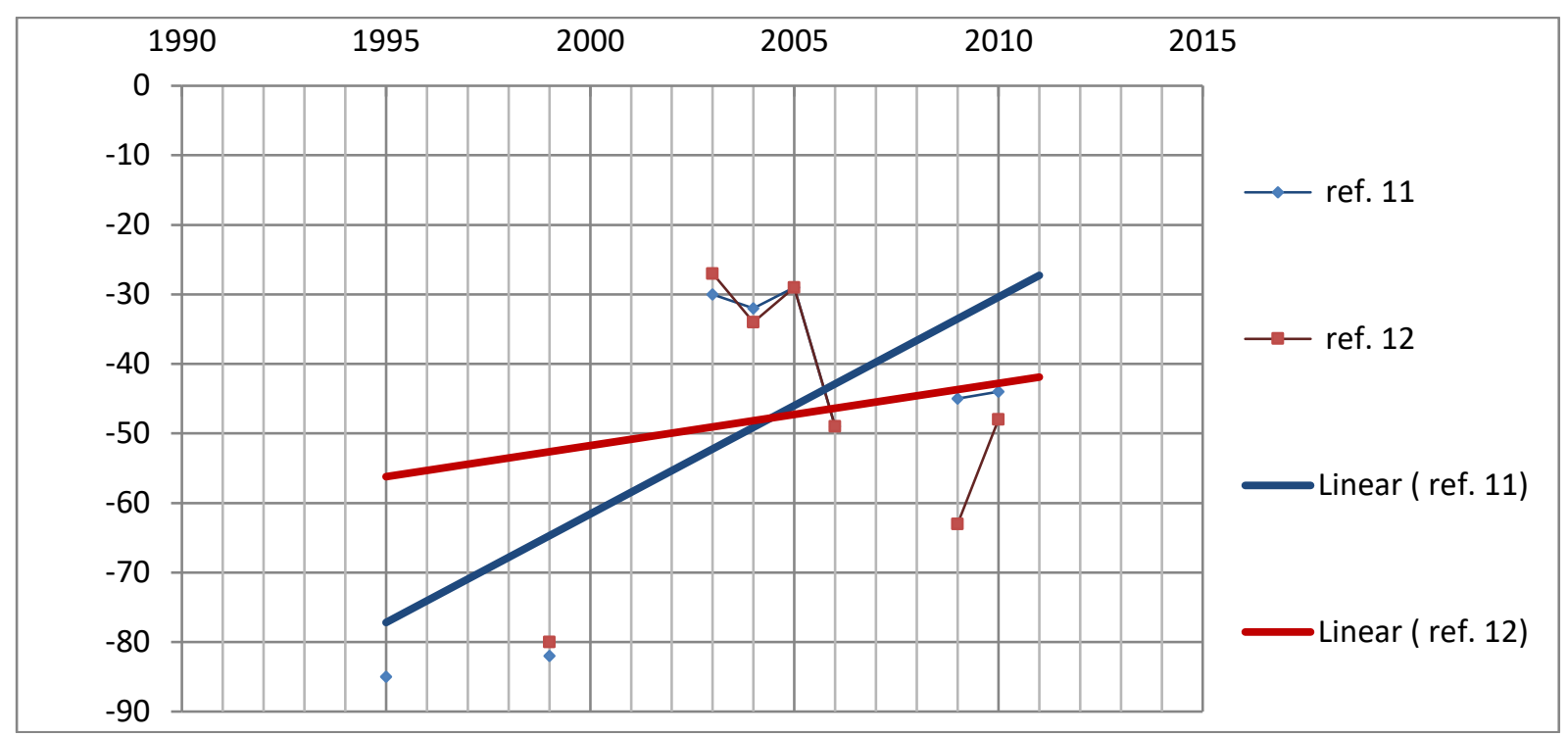

Figure 8: References 11 and 12 SWL (static water level) changes by the year

The groundwater level of 1, 3 and 4 reference points in the west of Kralk1zı dam have been on the rising trend since 1995. After the years between 1997 and 2000 when dam started to retain, groundwater level has increased and displayed periodical changes.

The groundwater level has sharply went up in the 9, 10 and 11 reference points remaining at the two dam sites and SWL around approximately 40-45 meters scaled up.

The groundwater level of reference 8 point in the east of Dicle dam began to increase with the building of dam. The water level has had a tendency to decrease after 2006 although it has still stayed on higher levels.

Even though the groundwater level of Reference 7 point in infra part of Dicle dam had scaled up after 2002, it has had a tendency to decrease since 2007.

Reference 5 and 6 points under the dam where slightly located further of south had gone up since 2002; however, the site became agricultural area in 2007 and with its effect SWL began to diminish.

\section{CONCLUSION}

Evaluating in general, it can be said that the dams contribute to raise level of the groundwater resources. Besides, it is observed that the water level within the basins of the dams arises significantly then stays at a constant level while the effect of the dams on the basins far from them decreases by the time. There is undeniable expectation groundwater rise in the dam's reservoir slope. When the groundwater could not find the way to exit at reservoir slope, it swarms to its shoulder, therefore the level of groundwater in the slope area dominate on the reservoir level.

The dams are the reason for rising of groundwater level. Especially, Upstream and Downstream sides and the side near the Reservoir groundwater level rises. Besides, the influence of dams cause on Static Water Level (SWL) declines where the lake of dam move away from its axis. Dams also cause to raise groundwater level in cultivated area via its irrigation.

Although, the main effect of the dams is increasing the groundwater substantially especially in the vicinity of the dams. But the effect of the dams is not the main parameter on groundwater level changes as moving away from dams. Groundwater level changes also depend on other factors as well as climatic changes, the period of precipitation and its changes, topographical structure of the region and especially human factor meaning obtaining the agricultural irrigation from the groundwater resources, etc.

\section{REFERENCES}

Ashraf, M., Hassan, F.U., Khan, M.A., 2000. Sustainable environment management: impact of agriculture. J. Sci.Tech. Develop. $19,51-57$.

Ashraf,M., Kahlown, M.A.,Ashfaq,A., 2007.Impact of small dams on agriculture and Groundwater development: A case study from Pakistan. A g r i c u 1 t u r a 1 water management $92,90-98$

Baxter, R. M. (1977). Environmental effects of dams and impoundments. Annual Review of Ecology and Systematics, $255-283$.

Brainwood, M. A., Burgin, S., \&Maheshwari, B. (2004). Temporal variations in water quality of farm dams: impacts of land use and water sources. Agricultural Water Management, 70(2), 151-175. 
Çelik, R. (2014). Mapping of groundwater potential zones in the Diyarbakır city center using GIS. Arabian Journal of Geosciences, $1-8$.

Çelik, R. (2015). Temporal changes in the groundwater level in the Upper Tigris Basin, Turkey, determined by a GIS technique. Journal of African Earth Sciences, 107, 134-143.

Elango, L. (2014). Impact of recharge from a check dam on groundwater quality and assessment of suitability for drinking and irrigation purposes. Arabian Journal of Geosciences, 7(8), 3119-3129.

Keller, A., Sakthivadivel, Seckler, R.D., 2000. Water scarcity and the role of storage in development. International Water Management Institute (IWMI) Research Report No. 39.

Martínez, A., Larrañaga, A., Basaguren, A., Pérez, J., Mendoza-Lera, C., \&Pozo, J. (2013). Stream regulation by small dams affects benthic macroinvertebrate communities: from structural changes to functional implications. Hydrobiologia, 711(1), 31-42.

Malkawi, A. I. H., \& Al-Sheriadeh, M. (2000).Evaluation and rehabilitation of dam seepage problems. A case study: Kafrein dam. Engineering Geology,56(3), 335-345.

Sinokrot, B. A., Stefan, H. G., McCormick, J. H., \& Eaton, J. G. (1995).Modeling of climate change effects on stream temperatures and fish habitats below dams and near groundwater inputs. Climatic Change, 30(2), 181-200.

Turkmen, S. (2003). Treatment of the seepage problems at the Kalecik Dam (Turkey). Engineering Geology, 68(3), 159-169.

Westbrook, C. J., Cooper, D. J., \& Baker, B. W. (2006). Beaver dams and overbank floods influence groundwater-surface water interactions of a Rocky Mountain riparian area. Water Resources Research, 42(6).

Wikipedia. available on: [http://en.wikipedia.org/wiki/Dicle_Dam] [accessed at 05/01/2014]

Wikipedia. available [http://en.wikipedia.org/wiki/Kralk\%C4\%B1z\%C4\%B1_Dam] [accessed at 05/01/2014]

Winter, T. C. (1999).Relation of streams, lakes, and wetlands to groundwater flow systems. Hydrogeology Journal, 7(1), 28-45. 